\title{
OPTIMIZERS FOR SUB-SUMS SUBJECT TO A SUM- AND A SCHUR-CONVEX CONSTRAINT WITH APPLICATIONS TO ESTIMATION OF EIGENVALUES
}

\author{
A. KovačEC, J. K. Merikoski, O. Pikhurko, A. Virtanen
}

Abstract. A complete solution is presented for the problem of determining the sets of points at which the functions $\left(x_{1}, \ldots, x_{n}\right) \mapsto x_{k}+\ldots+x_{l}$, subject to the constraints $M \geqslant x_{1} \geqslant \ldots \geqslant$ $x_{n} \geqslant m, x_{1}+x_{2}+\ldots+x_{n}=a$, and $g\left(x_{1}\right)+g\left(x_{2}\right)+\ldots+g\left(x_{n}\right)=b$, with $g$ strictly convex continuous, assume their maxima and minima. Applications are given.

Mathematics subject classification (2000): 90C25, 26D15, 15A42.

Key words and phrases: Optimization, Schur-convexity, eigenvalue estimation.

\section{REFERENCES}

[1] R. B. BAPAT, Majorization and singular values III, Linear Algebra Appl. 145: 59-70 (1991).

[2] M. BERGER, Geometry I, Springer, 1987.

[3] J. M. BorweIn AND A. S. LewIS, Convex Analysis and Nonlinear Optimization, Springer, 2000.

[4] J. M. BorWEIn, G. P. H. STYAN AND H. WOLKOWICZ, Some inequalities involving statistical expressions: Solution to problem 81-10 of L. V. Foster, SIAM Review 24: 340-342 (1982). Reprinted in M. S. Klamkin (ed.), Problems in Applied Mathematics: Selections from SIAM Review, pp. 373-375, SIAM, 1990.

[5] B. Grone, C. Johnson, E. M. DE SÁ AND H. Wolkowicz, Improving Hadamard's inequality, Linear and Multilinear Algebra 16: 305-322 (1984).

[6] A. KovAČEC, Polyhedra of monotone $n$-tuples; Pré-publicação 01-17, Universidade de Coimbra, Departamento de Matemática, 2001.

[7] K. LeICHTWEISS, Konvexe Mengen, Springer, 1980.

[8] A. W. MARShall AND I. OlKIN, Inequalities: Theory of Majorization and its Applications, Academic Press, 1979.

[9] J. K. MERIKOSKI, H. SARRIA AND P. TARAZAGA, Bounds for singular values using traces, Linear Algebra Appl. 210: 227-254 (1994).

[10] J. K. MERIKoski, G. P. H. STYAN AND H. Wolkowicz, Bounds for ratios of eigenvalues using traces, Linear Algebra Appl. 55: 105-124 (1983).

[11] J. K. MERIKOSKI, U. URPALA AND A. VIRTANEN, Upper bounds for the ratios of the largest and smallest eigenvalues, Department of Mathematical Sciences, University of Tampere, Report A 307, 1996.

[12] J. K. Merikoski, U. Urpala, A. Virtanen, T. Y. Tam and F. Uhlig, A best upper bound for the 2-condition number of a matrix, Linear Algebra Appl. 254: 355-365 (1997).

[13] J. K. MERIKOSKI AND A. ViRTANEN, Bounds for eigenvalues using the trace and determinant, Linear Algebra Appl. 264: 101-108 (1997).

[14] J. K. MERIKOSKI AND H. WOLKOWICZ, Improving eigenvalue bounds using extra bounds, Linear Algebra Appl. 68: 93-113 (1985).

[15] A. W. RoberTs and D. E. VARBerg, Convex Functions, Academic Press, 1973.

[16] R. T. Rockafellar, Convex Analysis, Princeton University Press, 1970.

[17] H. WolKowicz AND G. P. H. STYAN, Bounds for eigenvalues using traces, Linear Algebra Appl. 29: 471-506 (1980).

[18] H. WOLKOWICZ AND G. P. H. STYAN, More bounds for eigenvalues using traces, Linear Algebra Appl. 31: 1-17 (1980). 